\title{
A Neuroscientific Study of the Brain Stimulator and Simulation Model to Predict Breakfast PPG Using GH-Method: Math-Physical Medicine
}

\section{Gerald C Hsu*}

eclaireMD Foundation, USA

*Corresponding Author: Gerald C Hsu, eclaireMD Foundation, USA.

DOI: 10.31080/ASNE.2020.03.0204
Received: June 11, 2020

Published: July 30, 2020

(C) All rights are reserved by Gerald C Hsu.

\begin{abstract}
The author interprets the brain stimulator and its associated simulation model of predicted breakfast postprandial plasma glucose via a food or meal segmentation analysis and Sensor PPG waveform characteristics study. He has been using a continuous glucose monitoring device applied to his left upper arm and has collected 74 glucose data each day since 5/5/2018. However, by the mid-2019, he noticed that many of his post-breakfast glucose values escalated approximately one hour after the first bite of his breakfast, even when eating pure protein such as eggs without any carbs/sugar content. Therefore, during October of 2019, he modified his computer software to sort out different food contents and processed their associated PPG waveforms. By using a pure protein egg breakfast case study, this research paper offers some explanations to his speculation and hypothesis on how when eating food, this would prompt the brain to send an order to the liver to start the glucose production. This paper further links the functions of our brain, liver, and pancreas working together.
\end{abstract}

Keywords: Postprandial Plasma Glucose (PPG); Brain Stimulator; Simulation Model; GH-Method

\section{Introduction}

To prove his hypothesis in this paper, the author interprets the brain stimulator and its associated simulation model of predicted breakfast postprandial plasma glucose (PPG) via a food or meal segmentation analysis and Sensor PPG waveform characteristics study [1-4].

\section{Methods}

In his previous papers regarding brain functions and neuroscientific topics, he presented two hypotheses: weight is the major brain stimulator of fasting plasma glucose (FPG); and, carbs/sugar intake along with post-meal exercise are two major brain stimulators of PPG. In addition, he developed two different glucose simulation models to predict FPG and PPG, respectively.
The author has been using a continuous glucose monitoring device (CGM) applied to his left upper arm and has collected 74 glucose data each day since 5/5/2018. However, by the mid-2019, he noticed that many of his post-breakfast glucose values escalated approximately one hour after the first bite of his breakfast, even when eating pure protein such as eggs (without any carbs/sugar content). Therefore, during October of 2019, he modified his computer software to sort out different food contents and processed their associated PPG waveforms (i.e. curves).

Besides eating a plain cooked egg at home, he sometimes have his breakfast at McDonald's restaurants. This American fast-food chain offers some meals that do not increase PPG values too high because of the volume of its meals and limited variety of food selection. Usually, he eats one egg, one piece of sausage, occasionally half 
a muffin or one hash brown along with drinking one cup of coffee. As a comparison, he utilized the same segmentation analysis tool to analyze McDonald's breakfast as well.

\section{Results and Discussion}

He selected a period of 297 days (1/1/2019 - 10/24/2019) for his time window of glucose analysis. His average carbs/sugar intake amount for this total 297 breakfasts is 12.0 grams. During this period, he had 43 breakfasts of pure egg cooked at home $14 \%$ of total) with an average carbs/sugar intake amount of 1.4 gram only. He also had 131 breakfasts at McDonald's (44\% of total) with an average carbs/sugar intake amount of 11.1 grams.

He calculated and plotted out PPG waveforms associated with these three different breakfast segregations and displayed them in figure 1-3.

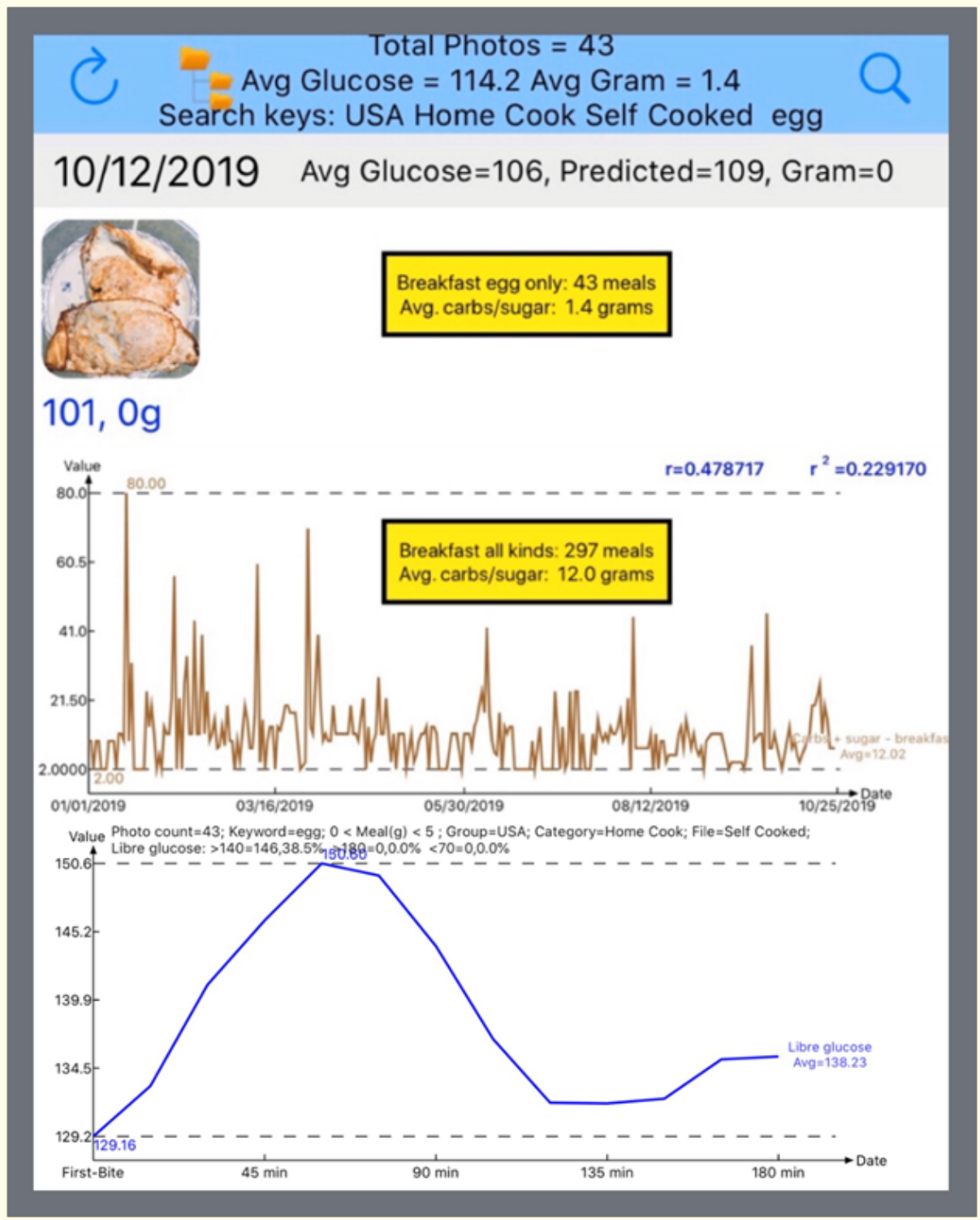

Figure 1: Egg case. 


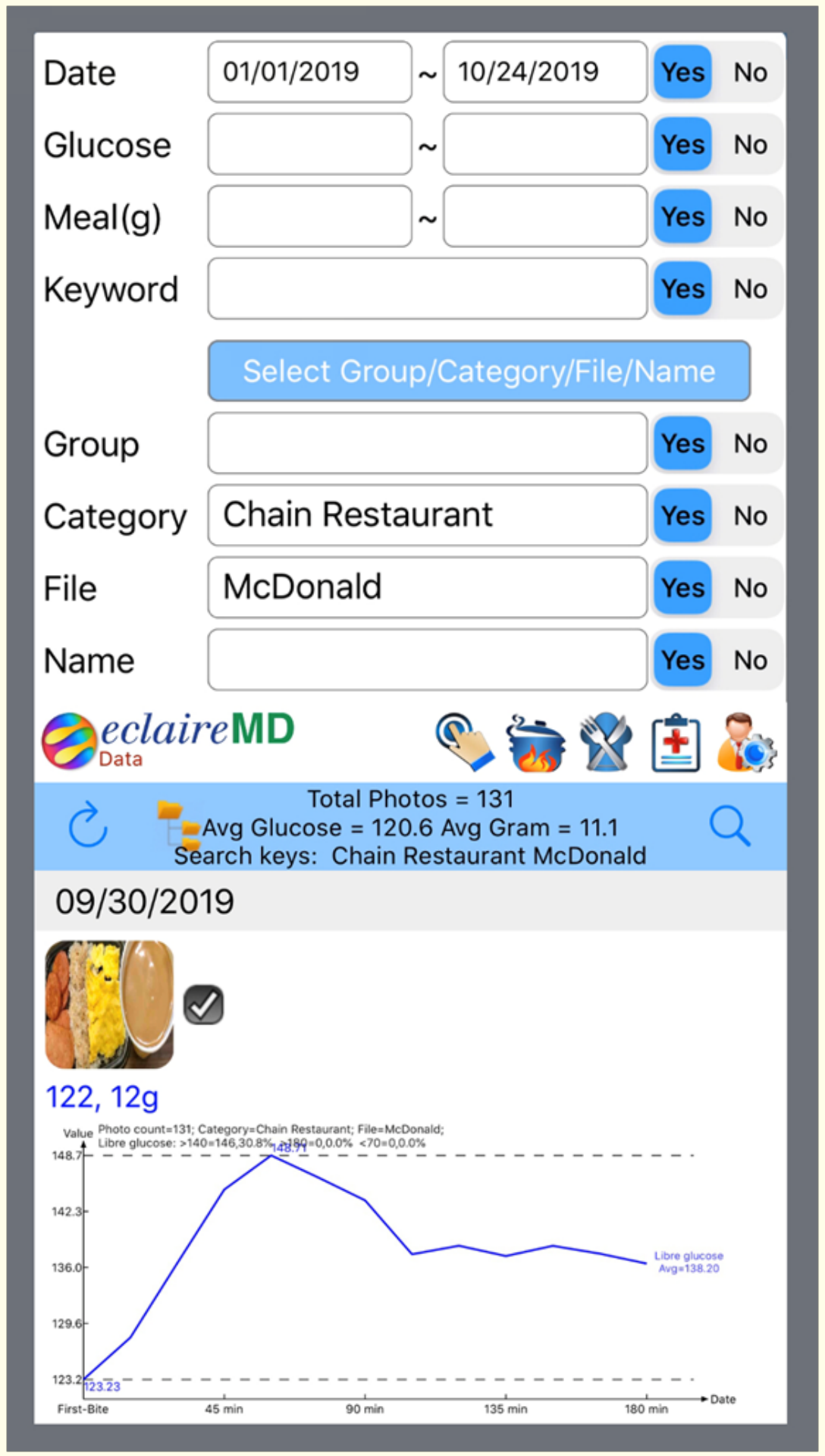

Figure 2: McDonald's case. 


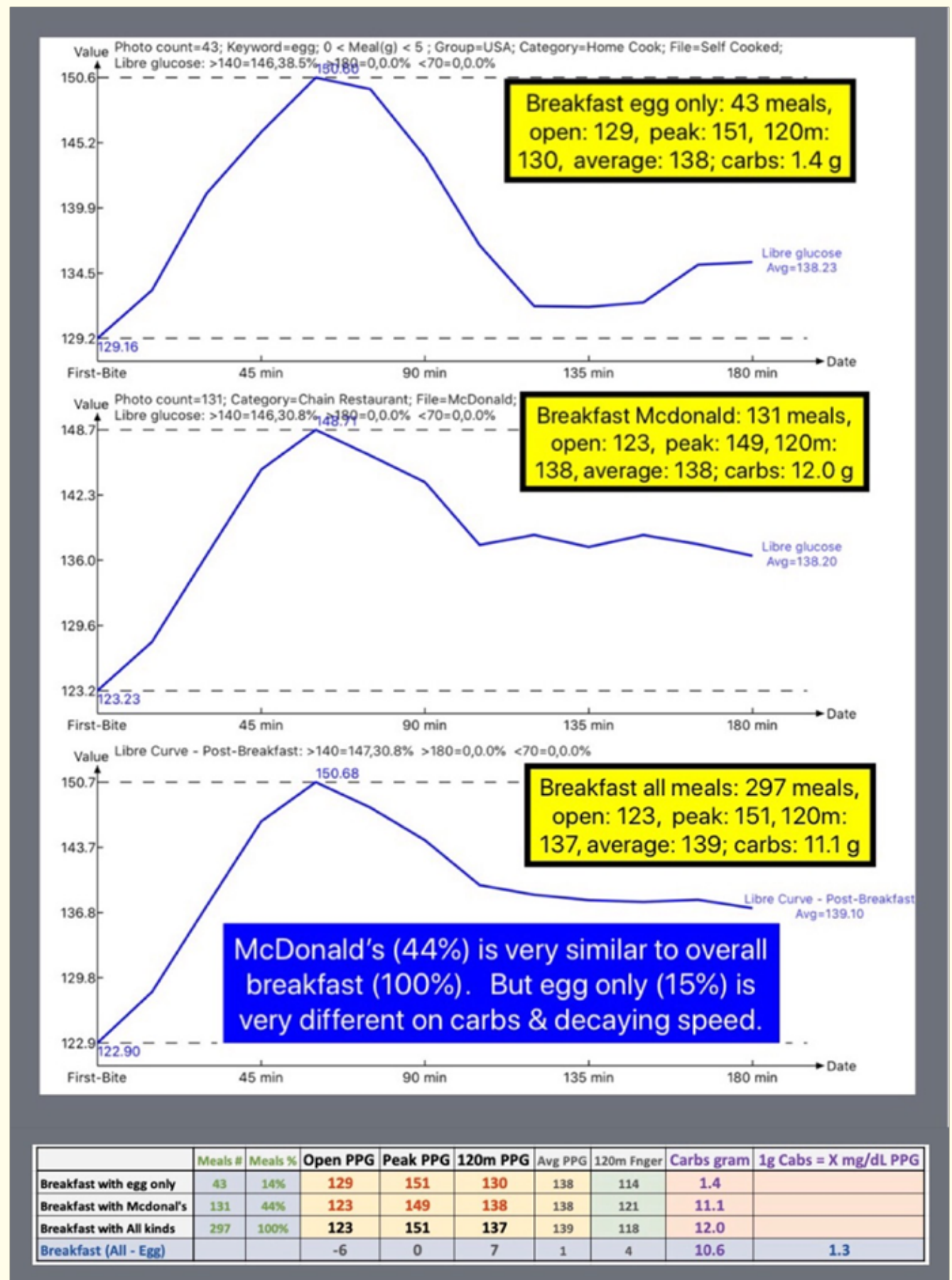

Figure 3: Comparison of egg, McDonald's, and overall cases.

Citation: Gerald C Hsu. "A Neuroscientific Study of the Brain Stimulator and Simulation Model to Predict Breakfast PPG Using GH-Method: Math-Physical Medicine". Acta Scientific Neurology 3.8 (2020): 11-15. 
The "Open" glucose, i.e. glucose at 0 minute, are $129 \mathrm{mg} / \mathrm{dL}$ (egg) and $123 \mathrm{mg} / \mathrm{dL}$ (McDonald's and overall). The "Peak" glucose at 60 minutes are149 mg/dL (McDonald's) and $151 \mathrm{mg} / \mathrm{dL}$ (egg and overall). The "End" glucose at 120 minutes are $130 \mathrm{mg} / \mathrm{dL}$ (egg), $138 \mathrm{mg} / \mathrm{dL}$ (McDonald's), and $137 \mathrm{mg} / \mathrm{dL}$ (overall). In summary, it does not matter what kind of breakfast he eats because his PPG would escalate from 123 - 129 level to 149 - 151 level within 60 minutes. This observed phenomenon has matched his hypothesis that the brain receives the incoming signal when food enters into his gastrointestinal system and then the brain issues an outgoing order to the liver for the production of glucose. However, after one hour, the brain will notice that this particular breakfast of only eggs without any extra "fuel" of carbs/sugar pumped into his body that is no further energy entering into his body. Based on the energy theory of mechanical engineering, his PPG value will decrease sharply to the "lowest" level of $130 \mathrm{mg} / \mathrm{dL}$ according to his simulation model of predicted PPG. This egg only case scenario is different from the other two cases of McDonald's and overall which would only drop to $137-138 \mathrm{mg} / \mathrm{dL}$ level.

It should be noted here that his post-meal walking exercise is maintained at a similar level for all of these three cases.

In addition, his calculated conversion factor between carbs/ sugar intake amount (gram) and generated Sensor PPG (mg/dL) is 1.25 which is very compatible with his previous findings of 1.2 as indicated in his published Sensor research paper.

\section{Conclusion}

By using a pure protein egg breakfast case study, this research paper offers some explanations to his speculation and hypothesis on how when eating food, this would prompt the brain to send an order to the liver to start the glucose production. However, the actual carbs/sugar intake amount and post-meal exercise will then come into the glucose simulation model later (around 60 minutes) to play their roles of finalizing PPG levels during one-hour to twohour period.

This paper further links the functions of our brain, liver, and pancreas working together.

\section{Bibliography}

1. Hsu Gerald C. "Using Math-Physical Medicine to Control T2D via Metabolism Monitoring and Glucose Predictions". Journal of Endocrinology and Diabetes 1.1 (2018): 1-6.
2. Hsu Gerald C. "Using Signal Processing Techniques to Predict PPG for T2D". International Journal of Diabetes and Metabolic Disorders 3.2 (2018): 1-3.

3. Hsu Gerald C. "Using Math-Physical Medicine and Artificial Intelligence Technology to Manage Lifestyle and Control Metabolic Conditions of T2D". International Journal of Diabetes and its Complications 2.3 (2018): 1-7.

4. Hsu Gerald C. "Using Math-Physical Medicine to Study the Risk Probability of having a Heart Attack or Stroke Based on Three Approaches, Medical Conditions, Lifestyle Management Details, and Metabolic Index". EC Cardiology 5.12 (2018): 925933.

\section{Assets from publication with us}

- Prompt Acknowledgement after receiving the article

- Thorough Double blinded peer review

- Rapid Publication

- Issue of Publication Certificate

- High visibility of your Published work

Website: www.actascientific.com/

Submit Article: www.actascientific.com/submission.php Email us: editor@actascientific.com

Contact us: +919182824667 